\title{
VỀ CƠ SỞ LÝ LUẬN ĐÀO TẠO BIÊN PHIÊN DỊCH Ở VIẸT NAM
}

\author{
Lê Hùng Tiến*
}

\author{
Trung tâm Ngôn ngũu và Quốc tế học, Trường Đại học Ngoại ngũu, ĐHQGHN, \\ Phạm Văn Đồng, Cầu Giấy, Hà Nội, Việt Nam \\ Nhận bài ngày 20 tháng 2 năm 2017
}

Chỉnh sửa ngày 20 tháng 3 năm 2017; Chấp nhận đăng ngày 22 tháng 3 năm 2017

Tóm tắt: Bài viết bàn về vấn đề phát triển cơ sở lý luận cho đào tạo biên phiên dịch chuyên nghiệp ở Việt Nam. Phần 1 của bài viết điểm qua những nét chính trong lịch sử và hiện trạng của đào tạo biên phiên dịch viên trên thế giới và Việt Nam, những mốc thay đổi trong nhận thức và lý luận về đào tạo biên phiên dịch dẫn tới những bước phát triển về đào tạo như hiện nay. Trong phần 2 , bài viết trình bày tóm tắt những khái niệm nền tảng của đào tạo biên phiên dịch như năng lực dịch thuật, năng lực biên phiên dịch viên, các loại chương tình đào tạo, đường hướng và phương pháp đào tạo, những thách thức với đào biên phiên dịch hiện nay trên thế giới và trong nước. Trên cơ sở phân tích những bất cập và yếu kém của đào tạo biên phiên dịch trong nước, bài viết đưa ra một số khuyến nghị về việc phát triển một cơ sở lý luận thích hợp cho đào tạo biên phiên dịch chuyên nghiệp ở Việt Nam.

Tù khóa: cơ sở lý luận, đào tạo biên phiên dịch, năng lực dịch thuật

\section{Hiện trạng đào tạo trên thế giới và ở Việt Nam}

\section{1. Đào tạo biên phiên dịch trên thế giới}

Vài nét về lịch sử phát triển

Tuy biên phiên dịch là một trong những nghề cổ xưa nhất của loài người (bằng chứng khảo cổ học ghi nhận biên phiên dịch xuất hiện từ 6-10 ngàn năm trước giữa các bộ lạc ở Trung Đông), việc đào tạo nghề biên phiên dịch một cách chính qui chỉ thực sự bắt đầu được một vài thập kỷ gần đây. Theo Pym (2009), từ Chiến tranh thế giới thứ hai, đào tạo nghề biên phiên dịch chính thống ở trường lớp với chương trình bài bản được thay cho đào tạo theo kiểu truyền nghề manh mún hoặc tự đào tạo trước đó. Đầu tiên là các trường đào tạo biên phiên dịch ở các nước nói tiếng Đức (Heidelberg năm 1930,

* ĐT.: 84-903216954, Email: letiena@yahoo.com
Geneva năm 1941 và Vienna năm 1943) phát triển nhanh chóng để phục vụ nhu cầu chiến tranh. Sau Chiến tranh thế giới thứ hai, do nhu cầu tìm hiểu kỹ thuật chế tạo bom và vũ khí của Đức của các nước thắng trận cùng với nhu cầu biên phiên dịch cấp bách của Tòa án quốc tế Nuremberg, nhiều chương trình và trường đào tạo biên phiên dịch ra đời ở châu Âu và Mỹ. Châu Âu có Graz và Innsbruck năm 1946, Germersheim năm 1947 và Saarbrücken năm 1948, Mỹ có Georgetown University năm 1949. Sự phát triển nhanh và mạnh mẽ phải kể đến là các chương trình và trường đào tạo biên phiên dịch của Pháp như ESIT và ISIT ra đời năm 1957 trước đòi hỏi của quá trình hợp nhất châu Âu lên mạnh lúc đó. Khác với trào lưu đáp ứng nhu cầu xã hội và thị trường ở Tây Âu, đào tạo biên phiên dịch ở Đông Âu bắt đầu sớm hơn và được gắn liền với các chương trình đào tạo ngoại 
ngữ như chương trình đào tạo biên phiên dịch ở Đại học tổng hợp ngôn ngữ Matxcơva Nga bắt đầu từ 1930. Mô hình đào tạo gắn với dạy ngoại ngữ này sau đó lan rộng và hiện còn duy trì ở nhiều nước Đông Âu.

Các nước phương Tây có xu hướng thành lập các trường chuyên đào tạo biên phiên dịch và chương trình đào tạo mang tính chuyên ngành cao. Các trường này thường mở các chương trình đào tạo phiên dịch hội nghị cao cấp và dịch thuật nói chung và đều là thành viên của Hiệp hội CIUTI (Conférence Internationale Permanente d'Instituts Universitaires de Traducteurs et Interprètes) thành lập năm 1964. Hiệp hội hiện có hơn 30 thành viên với nỗ lực không ngừng đảm bảo thương hiệu qua các chương trình đào tạo chất lượng ở hơn 300 trung tâm thuộc CIUTI chuyên đào tạo dịch thuật trên toàn thế giới, chiếm khoảng $10 \%$ thị phần đào tạo biên phiên dịch chuyên nghiệp của thế giới.

Tuy vậy, các chương trình đào tạo biên phiên dịch ngoài Tây Âu cũng phát triển nhanh chóng cạnh tranh mạnh mẽ với các chương trình Tây Âu từ những năm 1960 và đến những năm bảy mươi thế kỷ trước đã vượt Tây Âu về số lượng. Nguyên nhân chính của sự vượt trội này nằm ở nhu cầu xã hội và diễn biến của tình hình thế giới cuối thế kỷ 20 đầu thế kỷ 21. Tây Âu phát triển đào tạo biên phiên dịch nhằm phục vụ hàng loạt các nhu cầu khác nhau của quá trình hợp nhất châu Âu trong những năm này, trong khi các nước ngoài Tây Âu phát triển đào tạo biên phiên dịch chủ yếu để đáp ứng các nhu cầu của quá trình toàn cầu hóa kinh tế vốn ổn định hơn.

\section{Hiện trạng đào tạo biên phiên dịch}

Tuy có lịch sử phát triển khác nhau, nhưng đào tạo biên phiên dịch trên thế giới vẫn có một điểm chung là cùng chuyển đổi cách thức và loại hình đào tạo. Từ xu hướng cải cách đang làm thay đổi bản chất của đào tạo đại học là dần dịch chuyển trọng tâm sang các mục tiêu đào tạo nghề nghiệp, từng bước hòa nhập đào tạo biên phiên dịch vào cơ cấu đào tạo đại học. Các chương trình và trường đào tạo biên phiên dịch đang dần từ bỏ quan niệm đào tạo biên phiên dich chuyên nghiệp là thuộc các chương trình đào tạo đặc biệt (đào tạo đội ngũ 'elite') của các trường đào tạo nghề nghiệp chuyên biệt trước đây và đó cũng chỉ là các chương trình đào tạo đại học bình thường. Ngoài ra, các nhân tố tác động khác tới xu hướng cải cách đại học này còn là sự biến đổi về nhu cầu nhân lực và việc làm ở nhiều nước. Tỷ lệ thất nghiệp ở những người tốt nghiệp từ các trường đào tạo ngôn ngữ cao là hệ quả của toàn cầu hóa, việc dùng tiếng Anh phổ biến hơn khiến nhu cầu dùng các tiếng khác giảm nên giáo viên dạy các tiếng này ít việc làm hơn. Nhiều giáo viên ngoai ngữ tìm đến nghề biên phiên dịch hoặc để thay thế nghề dạy hoặc như một nghề bổ sung bán thời gian. Chính sách duy trì và phát triển các ngôn ngữ ít người nói của nhiều chính phủ, đặc biệt ở các nước đa dân tộc như Mỹ, Australia, Canada, Thụy Điển v.v. dẫn đến việc đào tạo hai ngoại ngữ trong đó biên phiên dịch đóng vai trò lớn hơn dạy tiếng để phục vụ cộng đồng, như biên phiên dịch tòa án, bệnh viện, sở di trú v.v.

Ở một số nước khác như Trung Quốc, nhu cầu của xã hội phát triển với biên phiên dịch chất lượng cao đang vượt xa năng lực đào tạo của hệ thống giáo dục do trước đây nước này đã không chú trọng đào tạo biên phiên dịch như một nghề nghiệp chính thống. Theo Liu (2013), các khóa đào tạo biên phiên dịch ở Trung Quốc được đặt hoàn toàn trong 
hệ thống đào tạo đại học và thuộc về các khoa đào tạo chuyên môn. Mặc dù chương trình đào tạo dịch thuật trình độ Thạc sĩ được bắt đầu từ những năm 1950 ở Trường Đại học Ngoại ngữ Bắc Kinh, nhưng phải đến 2007 chương trình đào tạo cử nhân biên phiên dịch mới bắt đầu cùng với những chương trình đào tạo nghề biên phiên dịch khác. Ở Hồng Kông, đào tạo biên phiên dịch chuyên nghiệp bắt đầu từ những năm 1970 với chương trình cử nhân biên phiên dịch của Trường Đại học Hồng Kông. Ân Độ hiện cũng đang nhận thấy sự thiếu hụt này cùng với đà phát triển và tăng trưởng kinh tế nhanh trong trào lưu toàn cầu hóa và nhiều trường đại học đang nỗ lực khắc phục hậu quả của việc đặt đào tạo dịch thuật ở biên của giáo dục đại học.

\section{Đánh giá và bằng cấp biên phiên dịch}

Hiện tại ở nhiều nước, việc đánh giá và cấp chứng chỉ hành nghề quốc gia được giao cho các tổ chức và hiệp hội nghề nghiệp. Hệ thống Chứng chỉ này độc lập với hệ thống bằng cấp chính thống của các trường đại học gồm Chứng chỉ nghề, Cử nhân, Thạc sĩ, Tiến sĩ vốn chỉ có giá trị tham khảo nhiều hơn là để hành nghề đối với giới sử dụng biên phiên dịch. Cơ quan đánh giá và cấp Chứng chỉ năng lực biên phiên dịch quốc gia ở Anh là Viện ngôn ngữ Anh Quốc (ILB), ở Mỹ là Hội Dịch thuật Hoa Kỳ (ATA), ở Úc là Tổ chức đánh giá biên phiên dịch quốc gia (NAATI), ở Thụy Điển là Viện Dịch thuật v.v. Ở những nước không có các tổ chức chuyên nghiệp thì việc tuyển dụng vẫn chủ yếu dựa trên hệ thống chứng chỉ và bằng cấp về biên phiên dịch ở các trường đại học và trường chuyên nghiệp.

\section{2. Đào tạo biên phiên dịch ở Việt Nam}

Ỏ Việt Nam, đào tạo biên phiên dịch một cách chính qui và bài bản ở các cơ sở đào tạo được bắt đầu khá muộn so với thế giới. Trước những năm 90 của thế kỷ 20, các khóa đào tạo biên phiên dịch được tổ chức một cách nhỏ lẻ ở các trường chuyên ngoại ngữ, ngoại giao và ngoại thương với chương trình đào tạo nặng về ngoại ngữ và một số ít môn học thực hành dịch theo hướng truyền nghề, với cơ sở khoa học thấp. Từ năm 2000, các khóa đào tạo biên phiên dịch chính qui mới được thực sự bắt đầu ở một số trường đại học như Trường Đại học Ngoại ngữ, Học viện Ngoại giao Việt Nam và Đại học Ngoại thương. Chương trình đào tạo phần lớn theo hướng Lục địa (chương trình cử nhân biên phiên dịch gồm 2 năm cơ sở và 2 năm chuyên ngành dịch) nhưng không đầy đủ, lấy đào tạo ngoại ngữ là chính với một hai học kỳ cuối tập trung vào đào tạo kỹ năng biên phiên dịch. Lúc đầu, sinh viên tốt nghiệp được cấp bằng Cử nhân tiếng nước ngoài chuyên ngành phiên dịch, nhưng sau ít năm, bằng cấp được đổi là Cử nhân tiếng nước ngoài chuyên ngành ngôn ngữ học. Mặc dù chương trình đã được cải tiến rất nhiều so với trước đây, nhưng nhìn chung vẫn thiên về đào tạo ngoại ngữ với một số học kỳ cuối tập trung vào lý luận và kỹ năng biên phiên dịch. Các khâu đào tạo chính từ thiết kế, quản lý thực hiện chương trình đến giảng dạy, kiểm tra đánh giá đều được tiến hành chưa thực sự bài bản, thiếu vắng lý luận cơ sở.

Các chương trình đào tạo biên phiên dịch ở Việt Nam vẫn chỉ ở cấp cử nhân và chưa có trường nào có chương trình đào tạo cấp cao hơn. Chưa có đánh giá chính thức nào về chất lượng đào tạo của các chương trình trong nước, nhưng một số sinh viên tốt nghiệp các chương trình đào tạo biên phiên dịch cho biết họ chưa có được vị thế cao khi gặp các nhà tuyển dụng ở các cơ quan, công ty trong nước.

Các co sở và chuơng trình đào tạo biên phiên dịch 
1. Trường Đại học Ngoại ngữ, Đại học Quốc gia Hà Nội: Chương trình được bắt đầu từ năm 1994 với 4 năm đào tạo chia thành 2 phần, mỗi phần 4 học kỳ được tiến hành xen kẽ không theo tuyến tính. Sinh viên tốt nghiệp được cấp bằng cử nhân ngoại ngữ chuyên ngành phiên dịch/ngôn ngữ học.

2. Trường Đại học Hà Nội: Chương trình 4 năm với 3 học kỳ cho biên dịch và 2 học kỳ dành cho phiên dịch, ngoài các học kỳ dành cho đào tạo ngoại ngữ. Sinh viên tốt nghiệp được cấp bằng cử nhân ngoại ngữ chuyên ngành phiên dịch/ngôn ngữ học.

3. Trung tâm đào tạo phiên dịch, Học viện Ngoại giao Việt Nam: Chương trình 3 tháng đào tạo biên phiên dịch viên dùng chương trình của cộng đồng châu Âu. Học viên tốt nghiệp được cấp Chứng chỉ biên phiên dịch.

4. Trường Đại học Hải Phòng: Chương trình 4 năm chia thành 2 phần, 4 kỳ đầu dành cho đào tạo ngoại ngũ̃, 4 kỳ sau cho đào tạo biên phiên dịch. Sinh viên tốt nghiệp được cấp bằng cử nhân chuyên ngành phiên dịch/ngôn ngữ học.

5. Trường Đại học Ngoại ngữ, Đại học Huế: Chương trình đào tạo liên kết với Học viện Ngoại giao Việt Nam, thời lượng 3 tháng và cấp Chứng chỉ biên phiên dịch.

Một số trường đại học khác ở phía Nam như Trường Đại học Ngoại ngữ - Đại học Đà Nẵng, Trường Đại học Khoa học Xã hội và Nhân văn Thành phố Hồ Chí Minh, Đại học Cần Thơ .v.v. cũng có các khóa đào tạo hệ phiên dịch cấp cử nhân tương tự các trường đại học phía Bắc nói trên.

Hiện trạng đào tạo trong nước cho thấy việc đào tạo biên phiên dịch cũng tương tự các nước châu Á khác (Trung Quốc, Ân Độ), đào tạo biên phiên dịch chuyên nghiệp vẫn chưa phải trọng tâm và ưu tiên của hệ thống đào tạo đại học và dạy nghề. Cấp đào đạo, nội dung và hình thức chương trình nghèo nàn, còn khá xa so với hiện trạng đào tạo ở các nước phát triển trên thế giới và yêu cầu của xã hội và thị trường trong nước.

\section{Năng lực dịch thuật và năng lực biên phiên dịch viên}

Để phục vụ đào tạo biên phiên dịch viên chuyên nghiệp, nhiều nghiên cứu dịch thuật và đào tạo dịch thuật nửa cuối thế kỷ 20 và đầu thế kỷ 21 đã tập trung làm rõ khái niệm 'năng lực dịch thuật' với nhiều định nghĩa và ý kiến khác nhau. Hiện trạng đào tạo biên phiên dịch trên thế giới cho thấy các loại hình chương trình và khóa đào tạo rất đa dạng, phản ánh những cách nhìn khác nhau về năng lực cần đào tạo cho biên phiên dịch viên. Về lý luận, các nhà nghiên cứu tương đối thống nhất với nhau rằng người hành nghề biên phiên dịch cần có hai loại kiến thức cơ sở là kiến thức thực thi hay phương pháp (operative or procedural knowledge) và kiến thức miêu tả hay thực tế (descriptive or factual knowledge). Hai loại kiến thức này cùng giúp biên phiên dịch viên phát triển năng lực phát hiện và giải quyết các vấn đề phức tạp trong quá trình dịch thuật mà bất kỳ cơ sở đào tạo biên phiên dịch viên chuyên nghiệp nào cũng cần tính tới khi thiết kế chương trình đào tạo.

Dựa trên sự thống nhất cơ bản trên, Kiraly (2000) phân biệt hai loại năng lực cơ bản trong biên phiên dịch là năng lực dịch thuật (translation competence) và năng lực biên phiên dịch viên (translator competence). Sự phân biệt này rất hữu ích trong đào tạo biên phiên dịch. Sau này hai loại năng lực này được Bernadini (2004) phát triển lên thành hai khái niệm là đào tạo biên phiên dịch (translator training) và giáo dục biên phiên dịch viên (translator education). Sự phân biệt này đặt nền móng cho việc thiết kế và phát 
triển các chương trình đào tạo biên phiên dịch ở các cấp độ khác nhau.

Về bản chất dịch thuật là một hoạt động phức tạp bao gồm sự hiểu biết và thành thạo ở nhiều lĩnh vực và kỹ năng. Để nghiên cứu và xác định năng lực dịch thuật, các tác giả thường phân chia năng lực này thành các năng lực thành phần để có thể xem xét riêng lẻ hoặc tổng thể. Năng lực bộ phận quan trọng nhất của năng lực dịch thuật được nhiều tác giả đề cập là năng lực ngôn ngữ, và hầu hết đều đồng ý rằng tuy đây là năng lực quan trọng bậc nhất nhưng không phải là tất cả. Nhìn chung, các nhà lý luận cho rằng các lĩnh vực bắt buộc tối thiểu của năng lực dịch thuật là kiến thức các ngôn ngữ, kiến thức các nền văn hóa và kiến thức của chuyên ngành liên quan. Các đặc điểm của chu cảnh của quá trình dịch thuật góp phần lớn tạo lập năng lực dịch thuật của biên phiên dịch viên.

\section{Năng lự dịch thuật}

Theo Neubert (2000), tính chất phức tạp của kiến thức và kỹ năng cần có của năng lực dịch thuật khiến cho nghề dịch thuật khác biệt nhiều với các nghề nghiệp khác. Ngoài ra, sự phức hợp của nhiều loại kỹ năng khác nhau của năng lực dịch thuật cũng góp phần tạo nên khác biệt cơ bản của nghề dịch. Tính tương đối của năng lực dịch thuật cũng là đặc diểm quan trọng cần kể tới. Biên phiên dịch viên cần có năng lực toàn diện về ngôn ngữ cùng với sự hiểu biết sâu về chuyên ngành để chuyển dịch được nội dung và hình thức của ngôn bản từ ngữ nguồn sang ngữ đích. Tuy vậy, họ vẫn không thể đạt tới trình độ chuyên gia về hiểu biết và kỹ năng của người phát và người nhận của ngôn bản. Từ đó có thể thấy là năng lực dịch luôn là năng lực mở và biên phiên dịch viên thường xuyên phải trau dồi qua nhiều nguồn tài liệu về kiến thức và tự nâng cao các kỹ năng ngôn ngữ cần có của diễn ngôn chuyên ngành. Người dịch trong công việc của mình luôn phải xử lý các khó khăn do khác biệt của ngôn ngữ và văn hóa như tìm hiểu nội dung ngữ nghĩa, tìm cách thức diễn đạt phù hợp ở ngôn ngữ và văn hóa mới v.v. nên cần có năng lực sáng tạo. Để thực hiện được những sáng tạo này, người dịch cũng cần tới sự nhận thức về các tình huống dịch thuật và các thay đổi rất linh hoạt của tình huống giao tiếp liên quan. Để xử lý các tình huống dịch mới, người dịch cũng phải dựa vào kinh nghiệm xử lý trong lịch sử nghề nghiệp, nên cần có kinh nghiệm xử lý hay còn gọi là lịch sử tính của năng lực dịch thuật.

Neubert (2000) xác định 5 loại năng lực thành phần cụ thể như sau: Năng lực ngôn ngữ, năng lực ngôn cảnh, năng lực chuyên ngành, năng lực văn hóa và năng lực chuyển dịch.

Năng lự ngôn ngũ: Nhiệm vụ của biên phiên dịch viên đòi hỏi phải có một năng lực ngôn ngữ ở mức độ gần như hoàn hảo về độ thành thục và sự tinh tế trên bình diện từ vựng, ngữ âm và ngữ pháp ở cả ngữ nguồn và ngữ đích. Thêm vào đó là ý thức nắm bắt được sự biến đổi thường xuyên ở cả hai ngôn ngữ trong giao tiếp thuộc lĩnh vực liên quan thể hiện qua từ điển và tài liệu chuyên ngành cùng hệ thống thuật ngữ của ngành ở hai ngôn ngữ.

Năng lục ngôn cảnh: Kiến thức và kỹ năng ngôn ngữ của người dịch luôn được gắn với năng lực diễn ngôn, tức là năng lực hiểu và tái tạo ngôn bản trong hoàn cảnh cụ thể để đạt mục đích giao tiếp, năng lực xử lý và kiến tạo ngôn bản trong sự hành chức. Ngoài kiến thức thông thường về ngôn ngữ, người dịch phải có được sự nhạy cảm về những đặc tính riêng của ngôn bản thể hiện ở từ vựng, cấu trúc được sử 
dụng theo các mẫu dạng đã thành thông lệ và có ý nghĩa riêng khi chúng hành chức trong văn bản giao tiếp thuộc chuyên ngành. Năng lực này được người dịch phát triển trong quá trình hành nghề trong một lĩnh vực chuyên ngành nào đó và ngày càng hoàn thiện ở cả hai ngôn ngữ và chuyên ngành liên quan.

Năng lục chuyên ngành: Đặc tính tương đối và mở của năng lực dịch thuật cho thấy người dịch phải có kiến thức chuyên ngành ở cả hai mức độ là kiến thức bách khoa và kiến thức chuyên sâu, nhưng không nhất thiết phải đạt tới trình độ chuyên gia. Kiến thức chuyên ngành này cũng không nhất thiết phải là kiến thức tích cực như ở chuyên gia mà chỉ cần đảm bảo là họ có khả năng tìm kiếm và trang bị cho mình đủ để chuyển dịch văn bản chuyên môn khi cần tới. Càng hành nghề lâu trong một chuyên ngành thì khoảng cách giữa kiến thức bách khoa của người dịch và kiến thức chuyên gia càng ngắn lại, giúp cho biên phiên dịch viên chuyển dịch nội dung và hình thức của văn bản chuyên ngành dễ dàng và chính xác hơn, với văn phong mang tính chuyên gia hơn.

Năng lực văn hóa: Văn bản, dù là văn bản kỹ thuật hay chuyên ngành hẹp, đều mang tính đặc thù văn hóa mà người dịch vốn là người có vai trò trung gian luôn nhận thấy qua các nét tương đồng và dị biệt trên văn bản. Ngay cả hệ thống thuật ngữ vốn ngày càng mang tính chất quốc tế vẫn mang đậm đặc thù văn hóa do hình thức ngôn ngữ của chúng đem lại, vì một ngôn ngữ không thể tách rời một nền văn hóa nào đó. Hình thức và thể loại văn bản luôn mang nặng đặc thù văn hóa, nên người dịch luôn phải biết cách chuyển dịch cho phù hợp với mẫu dạng của văn hóa nguồn và đích, dàn hòa được những bất đồng từ khác biệt văn hóa. Năng lực này được gọi là năng lực văn hóa của người dịch. Khi thực hiện chuyển dịch, người dịch có xu hướng thiên về nền văn hóa gốc của mình do họ vẫn thuộc về nền văn hóa đó trong cách tư duy và cảm nhận.

Năng lục chuyển dịch: Năng lực sử dụng được các thủ thuật và chiến lược chuyển đổi văn bản từ ngôn ngữ nguồn sang ngôn ngữ đích. Đây là năng lực quan trọng bậc nhất phân biệt biên phiên dịch viên với người song ngữ. Dù có được kiến thức và kỹ năng ngôn ngữ, ngôn cảnh, văn hóa và chuyên ngành sâu sắc và thành thạo nhưng thiếu năng lực chuyển dịch thì người song ngữ vẫn không thể kiến tạo được văn bản dịch một cách đầy đủ và phù hợp nhất cho người tiếp nhận đích. Xét đến cùng thì dịch thuật là một hoạt động dịch vụ cho giao tiếp và người dịch chỉ là người trung gian giữa bên phát và bên nhận. Do vậy, năng lực chuyển dịch giúp người dịch hiểu được đúng và đầy đủ các ý nghĩa của bên phát và chuyển dịch cho bên nhận một ngôn bản chứa đựng và chuyển tải được tối đa ý nghĩa với hình thức phù hợp với bên này.

Theo Neubert (2000), 5 năng lực thành phần kể trên kết hợp và tương tác với nhau tạo thành năng lực dịch thuật, làm cho dịch thuật khác biệt hẳn với những hoạt động và lĩnh vực giao tiếp khác. Trong những năng lực thành phần này thì năng lực chuyển dịch đóng vai trò bao trùm và quyết định tất cả sự thành bại của quá trình dịch thuật. Năng lực chuyển dịch chi phối và biến các hợp phần còn lại thành những nhân tố tích cực, hoạt động và thực thi chức năng của mình trong cả quá trình dịch thuật.

\section{Năng lục biên phiên dịch viên}

Theo Neubert (1989), đào tạo biên phiên dịch viên không chỉ giới hạn trong bốn bức tường của tháp ngà hàn lâm mà phải đáp ứng được nhu cầu của xã hội với nghề biên 
phiên dịch. Đây là một bước chuyển biến lớn về quan niệm nghề nghiệp cũng như đào tạo biên phiên dịch chuyên nghiệp ở nhiều cơ sở đào tạo trên thế giới. Quan niệm này cho thấy ngoài đào tạo năng lực dịch thuật nói chung, còn phải đào tạo cả con người làm nghề dịch thuật trong hoàn cảnh văn hóa xã hội cụ thể mà biên phiên dịch viên sẽ hành nghề. Như vậy, ngoài năng lực dịch thuật, chương trình đào tạo cần phát triển những năng lực khác mà biên phiên dịch cần có để làm nghề trong điều kiện và hoàn cảnh cụ thể của họ sau này. Theo Bernadini và Castagnoli (2004), ngoài năng lực dịch thuật, biên phiên dịch viên còn phải có được những kỹ năng liên nhân và thái độ, phẩm chất phù hợp với những đòi hỏi của nghề dịch thuật. Biên phiên dịch viên cần được học cách làm việc tương tác với các đồng nghiệp, với các nhà chuyên môn trong lĩnh vực, các nhà quản lý và khách hàng của mình. Họ cần biêt cách học và trau dồi kỹ năng và kiến thức cần thiết một cách thường xuyên qua công việc và những người liên quan. Họ cần được đào tạo cách tự tìm hiểu, phát hiện các chuẩn mực và các nguyên tắc đạo đức nghề nghiệp chủ yếu qua các nhiệm vụ chuyên môn và trao đổi với đồng nghiệp và những người liên quan khác. Giáo dục biên phiên dịch viên là phát triển năng lực của người phiên dịch đáp ứng đòi hỏi của nghề nghiệp và xã hội, giúp họ trở thành những công dân làm nghề đa năng hơn chỉ là những người có kỹ năng dịch thuật. Theo Liu (2013), ngoài những năng lực thành phần kể trên, biên phiên dịch viên chuyên nghiệp cần được hướng dẫn làm quen với môi trường và điều kiện làm việc mới bao gồm công cụ kỹ thuật hỗ trợ nghề biên phiên dịch như sử dụng cơ sở dữ liệu thuật ngữ, hệ thống ngăn làm việc (workbench), dịch với máy tính hỗ trợ, phần mềm nghiên cứu thông tin v.v.
Thêm vào đó là những hiểu biết và kỹ năng hành nghề như giao dịch với khách hàng, hợp đồng công việc, chuẩn nghề và chuẩn đạo đức trong nghề, kỹ năng viết kỹ thuật và kỹ năng hiệu đính, biên tập v.v. Những chương trình giáo dục biên phiên dịch viên chuyên nghiệp chính qui và dài hạn tập trung vào giúp học viên hình thành và phát triển năng lực biên phiên dịch viên, giúp họ trở thành thành viên của những cộng đồng của các ngành nghề và chuyên môn khác nhau cùng tham gia tạo nên sản phẩm dịch thuật.

Một chương trình giáo dục biên phiên dịch viên cần bao gồm các môn học phát triển được các năng lực thành phần và cuối cùng là năng lực tổng hợp nói trên để giúp biên phiên dịch viên thực hành nghề nghiệp biên phiên dịch ở mức độ cao nhất có thể.

\section{3. Đào tạo biên phiên dịch viên}

\subsection{Các đường huớng đào tạo biên phiên dịch}

Đào tạo biên phiên dịch chuyên nghiệp được các nhà lý luận chia thành 2 bình diện chính là giáo dục biên phiên dịch và đào tạo biên phiên dịch. Như đã bàn ở trên, đào tạo biên phiên dịch là huấn luyện và phát triển các năng lực phục vụ nghề nghiệp với trọng tâm là kiến thức, kỹ năng ngôn ngữ và kỹ năng biên phiên dịch, kết hợp giữa giảng dạy và thực hành ở các khóa học có định hướng dạy nghề thuần túy. Hướng này thường do các biên phiên dịch chuyên nghiệp chủ trương và trực tiếp tham gia đào tạo. Giáo dục biên phiên dịch là đào tạo ra các biên phiên dịch viên chuyên nghiệp với tư cách là những người hành nghề biên phiên dịch với thái độ, phẩm chất, kiến thức và kỹ năng thích hợp với nghề nghiệp theo yêu cầu của xã hội. Hướng này thường thực hiện ở các trường đại học với chương trình đào tạo chính qui và bài bản. 
Theo Pym (2009), các hướng đào tạo trên hợp thành 4 loại mô hình như sau:

Đuờng hưóng Luc địa (The Continental approach): Quá trình đào tạo được tiến hành như các khóa đào tạo đại học, theo hình thức của chương trình cử nhân biên phiên dịch. Chương trình gồm 2 năm cơ sở và 2 năm chuyên ngành dịch, sinh viên được đào tạo khá kỹ lưỡng về cả biên dịch và phiên dịch. Sau tốt nghiệp khóa cử nhân, học viên có thể học tiếp lên các khóa sau đại học.

Đuờng hương Anh quốc (The British approach): Nhiều trường đại học có các khóa đào tạo biên phiên dịch, nhưng hình thức tổ chức và trọng tâm đào tạo khác nhau rất lớn và rất khó để mô hình hóa hệ thống đào tạo này. Các chương trình đào tạo này cũng phổ biến ở Hoa Kỳ và khu vực không dùng tiếng Pháp của Canada. Các khóa học thuộc đường hướng này thường ngắn hạn từ 1 đến 2 năm và yêu cầu đầu vào với sinh viên là có kỹ năng tiếng ở mức thành thạo ở 2 ngôn ngữ.

Đuờng huớng định hương thị truờng (The market-oriented approach): Các khóa đào tạo theo sát với thị trường lao động do các đơn vị đào tạo hàn lâm hoặc phi hàn lâm tổ chức trên khắp thế giới với trọng tâm là đào tạo kỹ năng phiên dịch được qui định qua các tiêu chí của các tổ chức nghề nghiệp như AIIC (Tổ chức phiên dịch hội thảo quốc tế). Việc kiểm tra đánh giá năng lực phiên dịch và kiểm định chất lượng chương trình đều do các hội nghề nghiệp đảm nhận.

Đường hướng Scandinavia: Các khóa đào tạo do các hội đào tạo biên phiên dịch chuyên nghiệp châu Âu tổ chức thường có thời lượng 4 năm, sinh viên được lựa chọn khóa chuyên biên dịch và khóa chuyên phiên dịch. Người tốt nghiệp được cấp bằng Diploma về biên/phiên dịch và có thể theo học các khóa sau đại học. Các khóa đào tạo thuộc hệ thống này rất khác nhau về nội dung, phương pháp, mục tiêu với nhiều lựa chọn về ngôn ngữ nguồn và đích.

\subsection{Các mô hình chương trình đào tạo}

Theo Sawyer (2004), hiện tại có nhiều mô hình chương trình đào tạo biên phiên dịch viên trên thế giới, nhưng phổ biến vẫn là 5 mô hình chương trình:

Mô hình tuyến tính: Chia thành 2 giai đoạn: 1) Đào tạo năng lực biên phiên dịch cơ bản 2) Đào tạo năng lực biên phiên dịch nâng cao

Mô hình tuyến tính cải biên: 1) Đào tạo năng lực biên phiên dịch cơ bản 2) Đào tạo năng lực biên dịch nâng cao, trong đó một số ít được đào tạo năng lực phiên dịch nâng cao.

Mô hình song song: Cả hai nhánh đào tạo biên dịch và đào tạo phiên dịch được thực hiện song hành, như 2 chuyên ngành độc lập.

Mô hình chũ Y (Y-forked): 1) Đào tạo năng lực biên phiên dịch cơ bản 2) Đào tạo chia thành 2 nhánh chọn 1 : năng lực biên dịch nâng cao hoặc năng lực phiên dịch nâng cao.

Mô hình chũ Y (Y-forked) cải biên: 1) Đào tạo năng lực biên phiên dịch cơ bản 2) Đào tạo chia thành 3 nhánh chọn 1 : năng lực biên dịch nâng cao hoặc năng lực phiên dịch nâng cao hoặc năng lực ngôn ngữ chuyên ngành nâng cao.

\subsection{Phương pháp đào tạo}

Về mặt phương pháp, đào tạo năng lực biên phiên dịch thuần túy thường được biết tới với 2 đường hướng chính là đào tạo dựa trên nhiệm vụ (task-based training) và đào tạo dựa trên khối ngữ liệu song song (parallel corpora training). 


\section{Đào tạo dựa trên nhiệm vu}

Đường hướng này theo quan điểm của lý thuyết dạy ngôn ngữ dựa trên nhiệm vụ thực tế hay nhiệm vụ sư phạm như một đơn vị trong thiết kế chương trình dạy tiếng. Quan điểm chính của đường hướng này là người học sẽ học tốt nhất qua tương tác xã hội và giải quyết các vấn đề được mô phỏng như thực tế công việc của họ sau này. Cách dạy và học theo hướng này được áp dụng cho đào tạo biên dịch chuyên nghiệp đầu tiên ở Đại học Hawaii năm 1998 với khóa đào tạo biên phiên dịch Anh-Hoa. Chủ trương của cách dạy này là tổ chức nhiều nhiệm vụ hợp tác để người học làm việc nhóm cùng giải quyết vấn đề và kết quả đào tạo cho thấy nhiều mặt tích cực trong việc hình thành và phát triển năng lực dịch thuật cho người học. Quá trình dạy-học chính dựa trên khung làm việc gồm 4 bước:

Bước 1: Đánh giá chất lượng: Bao gồm các nhiệm vụ đánh giá bản dịch. Học viên được yêu cầu làm việc theo nhóm để đánh giá bản dịch theo các tiêu chí đánh giá một bài viết với trọng tâm là các vấn đề liên quan ngữ pháp tính của văn bản, cách diễn đạt, sự lưu loát, sự nhất quán và tính tự nhiên của văn bản. Sau đó văn bản gốc được so sánh với các tiêu chí tương tự nhưng tập trung hơn vào tính dễ hiểu, tin cậy và chính xác giữa bản gốc và bản dịch. Các tiêu chí đánh giá bản dịch là cơ sở để nhóm bàn bạc và kết luận về chất lượng dịch thuật.

Bước 2: Quá trình dịch. Nhóm được giao thực hiện các bài tập dịch theo các tiêu chí về chất lượng đã bàn ở bước 1 . Mục đích chính của bước này là giúp học viên thụ đắc các bước xử lý của dịch thuật chuyên nghiệp qua bàn bạc giải quyết các vấn đề khi thực hành dịch thuật theo các tiêu chí chất lượng của dịch chuyên nghiệp.

Bước 3: Dịch mạng (Web work): Học viên học cách dịch trên mạng qua việc thực hiện các kỹ năng đã học ở các bước trên vào dịch mạng. Ngoài việc học được các thuật ngữ chuyên ngành, họ còn học được các vấn đề liên quan đến dịch mạng. Sau đó học viên được giao các nhiệm vụ dịch thực tế các bài sẽ được sử dụng đưa lên mạng.

Bước 4: Đánh giá cuối cùng. Học viên được giao thực hiện dự án và dự thi cuối kỳ. Dự án tạo điều kiện cho họ tích hợp và thể hiện các kỹ năng và kỹ thuật đã hình thành trong cả quá trình học.

Phương pháp đào tạo dựa trên nhiệm vụ được coi là thích hợp với đào tạo biên dịch chuyên nghiệp với thế mạnh là giúp học viên hình thành và phát triển khá toàn diện các năng lực thành phần và năng lực dịch thuật tổng thể qua làm việc nhóm với nhiệm vụ thực tế dựa vào các tiêu chí chất lượng của dịch thuật chuyên nghiệp.

Đào tạo dựa trên khối liệu văn bản song song

Đào tạo dựa trên khối liệu là phương pháp đào tạo dùng khối liệu văn bản ngôn ngữ gốc và ngôn ngữ đích để giúp người học nhận biết và ứng dụng các chiến lược dịch khác nhau mà biên dịch viên chuyên nghiệp sử dụng để xử lý thông tin mang tính đặc thù văn hóa khi tạo dựng văn bản dịch từ văn bản gốc. Theo Pearson (2003), khối liệu văn bản phục vụ đào tạo năng lực dịch thuật gồm 2 loại hình là khối liệu khả sánh (comparable corpora) và khối liệu song song (parallel corpora). Khối liệu khả sánh chỉ gồm các văn bản cùng chủ đề ở ngôn ngữ gốc và ngôn ngữ đích. Khối 
liệu song song gồm các văn bản thuộc ngôn ngữ gốc và bản dịch của chúng ở ngữ đích. Các văn bản thuộc khối liệu này cho các bằng chứng về ngôn ngữ được hình thành trong môi trường song ngữ như thế nào. Qua xem xét các văn bản thuộc khối liệu song song, người học học hỏi được cách thức người dịch chuyên nghiệp xử lý khi tạo văn bản dịch trong khuôn khổ chế định của văn bản nguồn.

Các nhà nghiên cứu chủ trương đường hướng phương pháp này (Baker, 1995; Pearson, 2003; Zanettin, Bernardini và Stewart, 2014) nhấn mạnh vai trò to lớn của khối liệu song song trong đào tạo biên dịch viên và cho rằng những kết quả nghiên cứu dựa trên khối liệu song song là cơ sở lý luận và thực tiễn rất tốt cho thiết kế và thực hiện các chương trình đào tạo biên dịch viên. Theo Pearson (2003), những nghiên cứu về phương pháp đào tạo biên dịch dùng khối liệu song song cho thấy chương trình thiết kế theo đường hướng này rất thích hợp cho việc phát triển các chiến lược và kỹ thuật dịch văn bản có nhiều yếu tố văn hóa đặc thù và văn bản chuyên ngành.

\subsection{Những thách thức hiện tại với đào tạo biên phiên dịch}

\section{Những thách thức chung}

Theo Pym (2009) ba thách thức lớn với đào tạo biên phiên dịch hiện nay là phương pháp sư phạm, thiết kế chương trình và các nghiên cứu lý luận hỗ trợ. Phương pháp sư phạm của các trường đại học thường mang tính hàn lâm do ảnh hưởng của các chương trình đào tạo đại học và sau đại học sẵn có ở các ngành nghề khác nên phần nào tạo ra các sản phẩm xa rời nhu cầu thực của thị trường biên phiên dịch. Các trường đại học đang cố gắng thay đổi phương pháp và thiết kế chương trình đào tạo dịch thuật bằng cách đưa nhiều chuyên gia thực hành và biên phiên dịch viên chuyên nghiệp vào các lớp đào tạo biên phiên dịch, kết hợp với giáo viên hiện có. Tuy vậy, vẫn còn nhiều vấn đề nảy sinh khó khắc phục là chuyên gia thực hành và biên phiên dịch viên chuyên nghiệp thường thiếu cả phương pháp và kỹ năng sư phạm lẫn thời gian cho giảng dạy trong khi giáo viên đại học lại thiếu kỹ năng và kinh nghiệm thực hành và thực tế dịch trường.

Các nghiên cứu lý thuyết phục vụ đào tạo biên phiên dịch ít được chú ý so với những nghiên cứu đào tạo giáo viên ngoại ngữ, nên kết quả là các chương trình đào tạo và phương pháp đào tạo biên phiên dịch hiện nay còn đang thiếu vắng lý luận nền tảng chung. Từ những lý thuyết nền cơ bản như bản chất của năng lực biên phiên dịch, phương pháp luận đào tạo biên phiên dịch đến những lý luận phục vụ trực tiếp đào tạo biên phiên dịch như thiết kế chương trình đào tạo, phát triển học liệu, kiểm tra đánh giá năng lực biên phiên dịch, công nghệ hỗ trợ dich thuật v.v. đều đang cần nghiên cứu để phát triển tương ứng với sự phát triển của đào tạo. Hiện trạng trên là nguyên nhân chính cho việc sản phẩm đầu ra của các chương trình hiện tại tuy nhiều về số lượng nhưng vẫn chưa đáp ứng được nhu cầu đòi hỏi biên phiên dịch chuyên nghiệp chất lượng cao ở nhiều nước.

Một số nhà nghiên cứu (Mossop 2003, Robinson 2014) cho rằng đào tạo biên phiên dịch viên hiện tại đang chịu ảnh hưởng lớn của kỹ thuật và công nghệ hỗ trợ như dịch máy với cơ sở dữ liệu, các phần mềm dịch thuật và các hệ thống tổ chức nội dung văn bản. Tác động của các công nghệ này không còn dừng ở việc hỗ trợ công sức cho biên phiên dịch viên mà đang dần chuyển thành tác động thay đổi về chất công việc dịch thuật. Các công nghệ mới 
ngày càng thông minh hơn khiến biên phiên dịch viên lệ thuộc nhiều hơn vào chúng và hệ quả là công việc dịch thuật đang dần biến đổi về chất. Người dịch không còn chỉ nhờ tới công nghệ “đánh máy” hộ văn bản mà còn dịch hộ nhiều phần của văn bản, đặc biệt là những phần văn bản mang tính cố định. Người dịch từ chỗ làm việc với một văn bản tiếp nối và phát triển hoàn chỉnh đang chuyển thành người biên tập và lắp ghép các đoạn đã được viết sẵn bởi công nghệ. Một số nhà nghiên cứu thậm chí còn có những nhận định mạnh mẽ hơn là công nghệ đang dần biến đổi nghĩa của động từ "phiên dịch". Đây cũng đang là một thách thức đáng kể với đào tạo biên phiên dịch chuyên nghiệp trong tương lai.

Cuối cùng là những thách thức về kiểm tra đánh giá năng lực dịch thuật. Cách thức kiểm tra đánh giá cuối các khóa đào tạo dịch thuật thường chưa phản ánh được hết được những yêu cầu đa dạng của thực hành dịch thuật ngoài xã hội. Tình trạng chung ở nhiều nước là các chứng chỉ hành nghề dịch thường độc lập với bằng cấp về dịch thuật do các trường đại học cấp. Một số nước còn lập ra các tổ chức kiểm tra đánh giá dịch thuật độc lập. Điều đó cho thấy là bằng cấp về dịch thuật ở các trường đại học chưa được các tổ chức, cơ quan tuyển dụng biên phiên dịch đánh giá cao.

Nhũng thách thức với đào tạo biên phiên dịch chuyên nghiệp ở Việt Nam

Có thể nói đào tạo biên phiên dịch chuyên nghiệp ở Việt Nam đang trải qua những bước đi của thế giới cách đây vài thập kỷ. Chúng ta đang ở giai đoạn với những cách làm thử và sai đầy cảm tính, thiếu vắng lý luận cơ bản của thế giới trước đây. Các khóa đào tạo biên phiên dịch được mở ra ồ ạt ở các trường đại học ngoại ngữ khắp cả nước khoảng 1, 2 thập kỷ gần đây để đáp ứng nhu cầu xã hội (thực ra là nhu cầu bằng cấp của người học) đã dần mất uy tín với các nhà tuyển dụng. Các khóa ngắn hạn tổ chức ở các trung tâm ngoại ngữ lại càng yếu kém về chất lượng chuyên môn, ở nhiều nơi đó chỉ là những khóa học ngoại ngữ biến tướng không liên quan gì tới đào tạo năng lực biên phiên dịch. Hiện có rất ít khóa học ở một vài đại học lớn đào tạo được biên phiên dịch đúng hướng của quốc tế.

Tình trạng tụt hậu nói trên đang đặt ra nhiều thách thức lớn cho đào tạo biên phiên dịch nước ta. Ngoài ba thách thức trên của thế giới, đào tạo dịch thuật nước ta đang có nhiều tồn tại đặc thù của cách đào tạo thiếu bài bản, manh mún mạnh ai nấy làm, thiếu vắng và coi nhẹ lý luận chung của thế giới. Trước hết, đào tạo biên phiên dịch chuyên nghiệp trong nước đang rất cần một cơ sở lý luận dẫn đường dựa trên những nghiên cứu bài bản, hòa nhập lý luận quốc tế và dựa trên dữ liệu từ hoàn cảnh Việt Nam. Những nghiên cứu điều tra yêu cầu cụ thể với biên phiên dịch chuyên nghiệp ở Việt Nam rất cần được tiến hành để giúp cho việc xây dựng chương trình khung, thiết kế chương trình chi tiết, phát triển tài liệu dạy học, phương pháp dạy và các vấn đề liên quan khác như tổ chức khóa học, lớp tập huấn, kiểm tra đánh giá năng lực dịch thuật v.v.

Tiếp theo, đội ngũ giáo viên tham gia đào tạo đang là vấn đề lớn. Sự phát triển có phần thiên lệch theo hướng đào tạo giáo viên ngoại ngữ trong những năm qua ở các trường ngoại ngữ đã có ảnh hưởng nhiều tới đào tạo biên phiên dịch. Các trường, trước sức ép phải đào tạo biên phiên dịch, đã không tính đến đặc thù của phân ngành đào tạo này nên đã chuyển 
giao và áp dụng gần như nguyên xi từ chương trình đến giáo viên và phương pháp đào tạo từ hệ đào tạo giáo viên ngoại ngữ sang hệ đào tạo biên phiên dịch. Hậu quả là sản phẩm đầu ra của chương trình không đáp ứng nhu cầu và kỳ vọng của xã hội như đã nói ở trên. Người thiết kế chương trình, giáo viên dạy ngoại ngữ và giáo dục ngọai ngữ có rất ít kiến thức, kinh nghiệm của giáo viên và huấn luyện viên đào tạo biên phiên dịch nên các cơ sở đào tạo không thể có được chương trình, giáo viên, tập huấn viên phù hợp. Trong khi đó, giới biên phiên dịch viên chuyên nghiệp rất ít người có điều kiện tham gia đào tạo, chưa kể nếu có thì họ cũng thiếu kiến thức lý luận và kỹ năng nghiệp vụ sư phạm cần thiết cho giảng dạy và huấn luyện. Một đội ngũ giáo viên và tập huấn viên được đào tạo bài bản, vừa có lý luận vừa có kỹ năng, kinh nghiệm của dịch thuật và sư phạm dịch thuật để thực hiện chương trình đào tạo biên phiên dịch chuyên nghiệp đang là một đòi hỏi cấp thiết cho các cơ sở đào tạo dịch thuật ở nước ta.

Nhận thức của các nhà quản lý đào tạo về hệ đào tạo này cũng đang là một thách thức. Đa số ở các cơ sở đào tạo các khóa đào tạo biên phiên dịch chỉ được coi như một nhánh đào tạo phụ tách ra từ hệ đào tạo chính là dạy ngoại ngữ và đào tạo giáo viên ngoại ngữ nên ít được chú trọng đầu tư từ nhân sự tới vật chất tương xứng với hệ đào tạo có rất nhiều đặc thù này. Có thể thấy rất ít nhà quản lý biết là về bản chất, đào tạo biên phiên dịch chuyên nghiệp rất khác biệt so với đào tạo ngoại ngữ và giáo viên ngoại ngữ. Sự khác biệt lớn nhất là ở tính chất chuyên môn đặc biệt, có phần "elite" không mang tính đại chúng của năng lực dịch thuật và nghề biên phiên dịch. Sự nhận thức chưa đầy đủ này đã dẫn tới những quyết sách không phù hợp về đầu tư nhân lực và vật lực cho việc phát triển và thực hiện chương trình đào tạo biên phiên dịch. Kết quả là các chương trình và khóa đào tạo biên phiên dịch chuyên nghiệp trở thành các chương trình đào tạo mang tính đại trà, thiếu khoa học về mặt lý luận và bất cập ở phương diện thực hành nên việc sản phẩm đầu ra còn khá xa chuẩn là điều dễ hiểu.

Để khắc phục được những bất cập nêu trên, theo chúng tôi cần rất nhiều nỗ lực của những người liên quan ở mọi giới, từ nghiên cứu đến đào tạo và quản lý. Vấn đề quan trọng nhất là chúng ta phải bắt đầu từ một nhận thức thích hợp dựa trên những thông tin đầy đủ về lý luận và thực tiễn của phân ngành đào tạo mang nhiều đặc thù và còn ít được biết tới này, từ đó có thể tránh được lối mòn mò mẫm và tốn phí vô ích của thử và sai. Trên cơ sở đó các cơ sở đào tạo có thể đi tắt đón đầu và hòa nhập sớm vào cách làm chung đã có nhiều đổi mới của đào tạo biên phiên dịch chuyên nghiệp trên thế giới.

\section{Tài liệu tham khảo}

Baker, M. (1995). Corpora in translation studies: An overview and suggestions for future research. Target 72, 223-244.

Bernardini, S., Castagnoli, S. (2008). "Corpora for translator education and translation practice”. In: E. Yuste Rodrigo (ed.). Topics in Language Resources for Translation and Localisation. Amsterdam/Philadelphia: John Benjamins.

Liu, J. (2013). Translators Training: Teaching Programs, Curricula, Practices. Academy Publisher, Finland.

Kiraly, D. (2000). A Social Constructivist Approach to Translator Education: Empowerment from Theory to Practice. Manchester: St. Jerome Publishing. 
Mossop, B. (2003). "School, practicum and professional development workshop: toward a rational sequence of topics" in $\mathrm{La}$ formation à la traduction professionnelle, Ottawa: University of Ottawa Press, 47-61.

Neubert, A. (2000). Competence in Language, in Languages, and in Translation. In Schäffner, C. and B. Adab (Eds.). Developing Translation Competence. Amsterdam: John Benjamins

Neubert, A. (1989). Supporting teacher research. Teacher Educator, 25(1) 2-9. EJ407848, Educational Resources Information Center (ERIC).
Pearson, J. (2003). Using parallel texts in the Translator Training Environment. In Zanettin, F., Bernardini, S. \& Stewart, D (Eds.). Corpora in Translator Education. Manchester: St Jerome Publishing.

Robinson, B. et al. (2014). The Professional Approach to Translator Training Revisited. Universidad de Granada.

Sawyer, B., D. (2004). Fundamental Aspects of Interpreter Education - Curriculum and Assessment. Amsterdam: John Benjamins Publishing Company.

Zanettin, Bernardini, Z. Stewart, D. (2014), Corpora in translation education, Routlegde.

\title{
ON A THEORETICAL FOUNDATION FOR PROFESSIONAL TRANSLATOR AND INTERPRETER TRAINING AND EDUCATION FOR VIETNAM
}

\author{
Le Hung Tien
}

Center of Linguistics and International Studies, VNU University of Languages and International Studies, Pham Van Dong, Cau Giay, Hanoi, Vietnam

\begin{abstract}
The paper addresses the need to develop a theoretical foundation for professional translator and interpreter training and education for Vietnam. Section 1 gives a brief outline of the history as well as the current development of translator and interpreter training in the world and in Vietnam. Section 2 presents the fundamental concepts in translation pedagogy such as translation competence, translator competence, types of training programmes and curricula, approaches and methods of training and translation assessment. Based on the analysis of the weaknesses in the current translation training of Vietnam some recommendations for the development of an appropriate theoretical foundation are made.
\end{abstract}

Keywords: theoretical foundation, translator and interpreter training, translation competence 